\title{
PHOTOCATALYTIC HYDROGENATION OF CARBON-CARBON TRIPLE BOND
}

\author{
${ }^{1}$ Anna ZABELINA, ${ }^{1}$ Denis ZABELIN, ${ }^{1}$ Vaclav ŠVORČíK, ${ }^{1,2}$ Oleksiy LYUTAKOV \\ 'VŠCHT - University of Chemistry and Technology, Prague, Czech Republic, EU, lyutakoo@vscht.cz \\ ${ }^{2}$ Tomsk Polytechnic University, Research School of Chemistry and Applied Biomedical Sciences, Tomsk, \\ Russian Federation
}

https://doi.org/10.37904/nanocon.2021.4334

\begin{abstract}
Hydrogenation reactions are one of the main reactions in the chemical industry. In this work, we have demonstrated a plasmon assisted hydrogenation, performed on bimetallic (Au@Pt) nanoparticles. Using phenylacetylene as an example, it was shown that plasmon accelerates the hydrogenation process and makes it possible at mold conditions with high conversion and reaction yield.
\end{abstract}

Keywords: Photocatalysis, hydrogenation, core-shell nanoparticles, selectivity, alkyne

\section{INTRODUCTION}

Selective hydrogenation of unsaturated organic compounds such as alkynes $(\mathrm{C} \equiv \mathrm{C})$ and aldehydes, ketones and esters $(\mathrm{C}=\mathrm{O})$ is a fundamental transformation in organic chemistry, commonly used in synthetic, petroleum and natural products chemistry [1,2]. Hydrogenation is usually carried out at elevated temperatures and with an external source of hydrogen at high pressure [3-5].

Selective hydrogenation, which excludes undesirable processes of hyperhydrogenation of organic compounds is especially technically important. Currently, there are two approaches to carrying out selective semihydrogenation - utilization of specific metal catalysts in combination with molecular hydrogen [6-8]. At the same time, hydrogen gas, which is usually used for hydrogenation at high pressures and temperatures, is a source of high danger, so it is more advisable to use another sources of hydrogen.

Therefore, from safety and selectivity points of view, the utilization of alternative hydride reagents such as lithium aluminum hydride $\left(\mathrm{LiAlH}_{4}\right)$, triethylsilane $(\mathrm{Et} 3 \mathrm{SiH})$ and sodium borohydride $\left(\mathrm{NaBH}_{4}\right)$ is suitable [9-13]. However, these compounds do not show sufficient activity in the hydrogenation of some organic groups and molecules. Here we have demonstrated plasmon-assisted photocatalysis, performed at mild conditions under visible light illumination. Generally, similar approach, i.e. plasmon assisted photocatalysis has attracted a lot of attention because the excitation of localized surface plasmon resonance (LSPR) accelerates wide range of relevant chemical transformations [14-17].

In this work, a highly selective photocatalytic hydrogenation of the $\mathrm{C} \equiv \mathrm{C}$ triple bond with bimetallic Au@Pt particles was carried out using sodium borohydride as a hydrogen source.

\section{EXPERIMENTAL}

\subsection{Materials}

Deionized water (EMD MILLIPORE), trisodium citrate, gold(III) chloride, L-Ascorbic acid (99\%), chloroplatinic acid solution (8 wt. \% in $\mathrm{H}_{2} \mathrm{O}$ ), Phenylacetylene, Sodium borohydride (99\%), Methanol $(\geq 99.9 \%)$ were ordered from Sigma-Aldrich and used without additional purification. 


\subsection{Sample preparation}

Gold nanoparticles were obtained by the Turkevich method [18]. After the preparation of the seed, Au was introduced into a round-bottom flask with a solution of platinum hydrochloric acid ( $8 \mathrm{wt} \% \mathrm{~B} \mathrm{H}_{2} \mathrm{O}$ ). The mixture was stirred for 20 minutes. Then L-ascorbic acid was added very slowly dropwise until the colour of the solution changed from red to black. Then the resulting bimetallic nanoparticles were washed three times with methanol.

The solution of Au@Pt in methanol and deionized water, was sonicated for 3 min after the addition of $0.13 \mathrm{mM}$ of phenylacetylene. The hydrogenation reaction of phenylacetylene was performed in thermal chamber under careful temperature control. Immediately before the experiment, 1.5 equivalents of $\mathrm{NaBH}_{4}$ were added to the reaction mixture.

The mixture was stirred and irradiated illuminated with LED ( $595 \mathrm{~nm}$ central emission wavelength). At the end of the experiment, nanoparticles were removed from the reaction mixture and reaction progress was monitored using gas chromatography.

\subsection{Measurement Techniques}

Ultraviolet-visible spectroscopy (UV-Vis) spectra were measured using Spectrometer Lambda 25 (PerkinElmer) in 300-1100 nm wavelength range. The nano-morphology of catalyst and the average particle size were analysed by high-resolution transmission electron microscopy HRTEM with Jeol 2200 FS microscope (Jeol, Japan). The conversion of reagents and products was analysed by gas chromatograph Agilent 8860 series GC system (Agilent Technologies, Inc., Wilmington, DE).

\section{RESULTS AND DISCUSSION}

Successful preparation of gold and bimetallic nanoparticles were examined using UV-Vis (Figure 1) and HRTEM-EDX (Figure 2) measurements. Gold nanoparticles show a peak of plasmon resonance located near $530 \mathrm{~nm}$. The addition of Pt led to the significant broadening of the absorption band and its shift to $586 \mathrm{~nm}$. The HRTEM image of the AuNPs (Figure 2A) shows a typical spherical shape with an average size about $30 \mathrm{~nm}$. In the case of Au@Pt NPs HRTEM result (Figure 2B) reveal a uniform dendritic shell (Pt) and spherical core $\mathrm{Au}$. Elemental mappings of $\mathrm{Au}$ and $\mathrm{Pt}$ also show the corresponding distribution of $\mathrm{Au}$ and $\mathrm{Pt}$ metals across the nanoparticle. For further experiments, an LED with emission wavelength of $595 \mathrm{~nm}$ was chosen, which corresponds to the Au@Pt peak in the UV-visible spectrum.

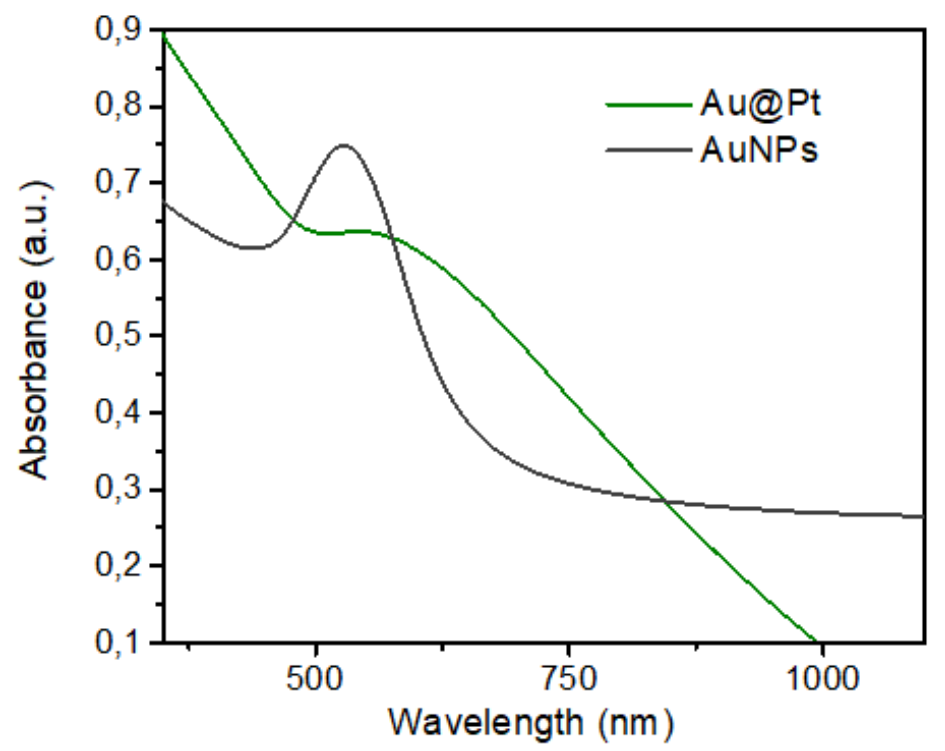

Figure 1 The UV-Vis absorption spectra of: AuNPs and Au@Pt NPs 

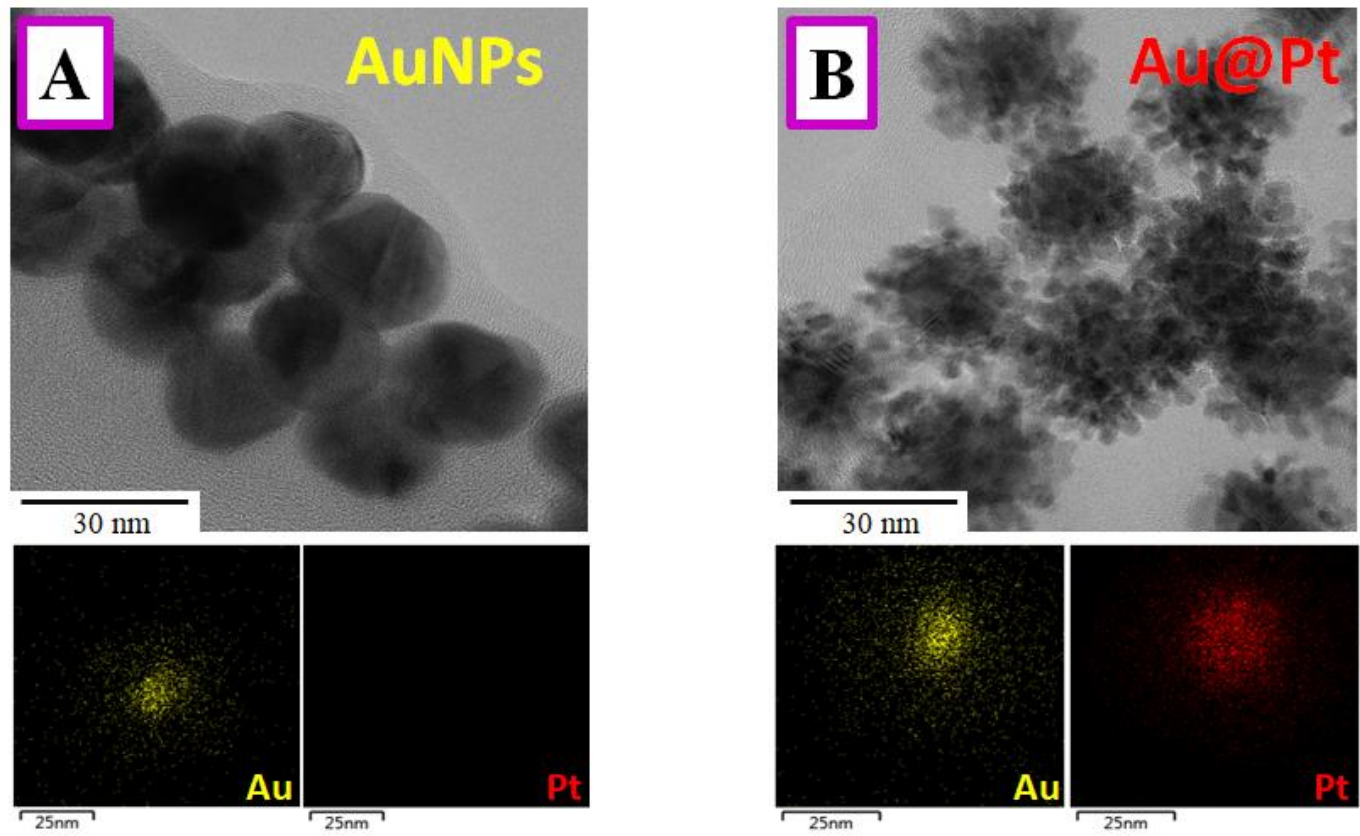

Figure 2 HRTEM-EDX images of $(A)$ - AuNPs and (B) - Au@Pt nanoparticles

The conversion and selectivity results were monitored by a gas chromatograph. Figure $\mathbf{3}$ shows the curves of the dependence of the conversion of phenylacetylene on the reaction time at room temperature in the dark and under irradiation with LEDs $(595 \mathrm{~nm})$. It is well visible that reaction progress is influenced by the illumination. In particular, in the absence of illumination, the reaction proceeds with a maximum conversion of $60 \%$ after $8 \mathrm{~h}$. and about $100 \%$ in the case of plasmon triggering.

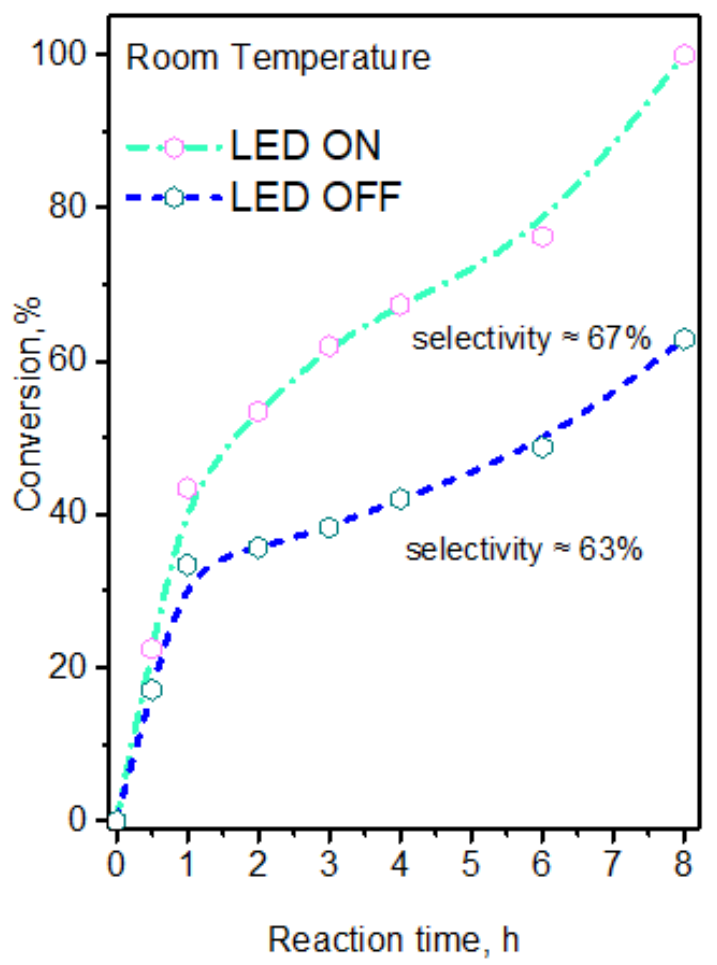

Figure 3 Dependence of Phenylacetylene conversion on the reaction time at RT in dark and under LED irradiation $(595 \mathrm{~nm})$ 


\section{CONCLUSION}

In this work, we have successfully carried out the hydrogenation of phenylacetylene under plasmon assistance. Reaction was performed with utilization of $\mathrm{NaBH}_{4}$ as a hydrogen source. Surface plasmon was excited on the bimetallic metal nanoparticles, which consist of plasmon active gold core and catalytically active Pt shell. The reaction conversion, closed to $100 \%$ was reached.

\section{ACKNOWLEDGEMENTS}

\section{This work was supported by the project Internal Grant Agency UCT No A2_FCHT_2021_086}

\section{REFERENCES}

[1] DE VRIES, J.G, ELSEVIER, C.J. The handbook of homogeneous hydrogenation. WeinheimWiley-VCH, 2007

[2] LIST, G.R., JACKSON, M., ELLER, F., ADLOF, R.O. Low trans spread and shortening oils via hydrogenation of soybean oil. Journal of the American Oil Chemists' Society. 2007, vol. 84, no.6, pp. 609-612.

[3] HUANG, Y., LIU, Z., GAO, G., XIAO, Q., MARTENS, W., DU, A., ZHU, H. Visible light-driven selective hydrogenation of unsaturated aromatics in an aqueous solution by direct photocatalysis of Au nanoparticles Catalysis Science \& Technology. 2018, vol. 8, no. 3, pp. 726-734.

[4] IMAMURA, K., OKUBO, Y., ITO, T., TANAKA, A., HASHIMOTO, K., KOMINAMI, H. Photocatalytic hydrogenation of alkenes to alkanes in alcoholic suspensions of palladium-loaded titanium (iv) oxide without the use of hydrogen gas. RSC Advances. 2014, vol. 4, no. 38, pp. 19883-19886.

[5] QUIROZ, J. ,BARBOSA, E. C., ARAUJO, T. P., FIORIO, J. L., WANG, Y. C., ZOU, Y. C., HAIGH, S. J. Controlling reaction selectivity over hybrid plasmonic nanocatalysts. Nano letters. 2018, vol. 18, no. 11, pp. 7289-7297.

[6] LU, Y., FENG, X., TAKALE, B. S., YAMAMOTO, Y., ZHANG, W., BAO, M. Highly selective semihydrogenation of alkynes to alkenes by using an unsupported nanoporous palladium catalyst: No leaching of palladium into the reaction mixture. ACS Catalysis. 2017, vol. 7, no. 12, pp. 8296-8303.

[7] ZHANG, X. B. Preparation of 1-phenylethanol by selective hydrogenation of acetophenone over aluminasupported Co catalysts. Reaction Kinetics, Mechanisms and Catalysis. 2011, vol. 102, no. 2, pp. 417-424.

[8] SANDOVAL, C. A., OHKUMA, T., MUÑIZ, K., NOYORI, R. Mechanism of asymmetric hydrogenation of ketones catalyzed by BINAP/1, 2-diamine- ruthenium (II) complexes. Journal of the American Chemical Society. 2003, vol. 125, no. 44, pp. 13490-13503.

[9] ELSEN, H., LANGER, J., BALLMANN, G., WIESINGER, M., HARDER, S. Alkaline Earth Metal Aluminates as Catalysts for Imine Hydrogenation. Organometallics. 2020, vol. 39, no. 23, pp. 4238-4246.

[10] TITOVA, Y.Y., SUKHOV, B.G., SCHMIDT, F.K. Nano-size bimetallic ternary hydrogenation catalysts based on nickel and copper complexes. Journal of Organometallic Chemistry. 2020, vol. 928, p. 121485.

[11] WÖLKE, C., DANILIUC, C. G., KEHR, G., ERKER, G. Diels-Alder route to norbornane derived vicinal phosphane/borane frustrated Lewis pairs for the metal-free catalytic hydrogenation of $\alpha, \beta$-unsaturated ketones. Journal of Organometallic Chemistry. 2019, vol. 899, p. 120879.

[12] JIA, W., XI, Q., LIU, M. T., YANG, CHEN, Y., YIN, D., WANG, X. One-pot synthesis of O-heterocycles or aryl ketones using an $\mathrm{InCl}_{3} / \mathrm{Et}_{3} \mathrm{SiH}$ system by switching the solvent. The Journal of organic chemistry. 2019, vol. 84, no. 9, pp. 5141-5149.

[13] WEN, X., SHI, X., QIAO, X., WU, Z., BAI, G. Ligand-free nickel-catalyzed semihydrogenation of alkynes with sodium borohydride: a highly efficient and selective process for cis-alkenes under ambient conditions. Chemical Communications. 2017, vol. 53, no 39, pp. 5372-5375.

[14] KALE, M. J., AVANESIAN, T., XIN, H., YAN, J., CHRISTOPHER, P. Controlling catalytic selectivity on metal nanoparticles by direct photoexcitation of adsorbate-metal bonds. Nano letters. 2014, vol. 14, no. 9, pp. 54055412.

[15] LINIC, S., ASLAM, U., BOERIGTER, C., MORABITO, M. Photochemical transformations on plasmonic metal nanoparticles. Nature materials. 2015, vol. 14, no. 6, pp. 567-576. 
[16] ZABELINA, A., ZABELIN, D., MILIUTINA, E., LANCOK, J., SVORCIK, V., CHERTOPALOV, S., LYUTAKOV, O. Surface plasmon-polariton triggering of $\mathrm{Ti}_{3} \mathrm{C}_{2} \mathrm{~T}_{\times} \mathrm{MXene}$ catalytic activity for hydrogen evolution reaction enhancement. Journal of Materials Chemistry A. 2021, vol. 9, no. 33, pp. 17770-17779.

[17] GUSELNIKOVA, O., POSTNIKOV, P., KOSINA, J., KOLSKA, Z., TRELIN, A., SVORCIK, V., LYUTAKOV, O. A breath of fresh air for atmospheric $\mathrm{CO}_{2}$ utilisation: a plasmon-assisted preparation of cyclic carbonate at ambient conditions. Journal of Materials Chemistry A. 2021, vol. 9, no. 13, pp. 8462-8469.

[18] KIMLING, J., MAIER, M., OKENVE, B., KOTAIDIS, V., BALLOT, H. AND PLECH, A. Turkevich method for gold nanoparticle synthesis revisited. The Journal of Physical Chemistry B. 2006, vol. 110, no. 32, pp.15700-15707. 